\title{
Image processing and reconstruction method based on broadband InfraRed to terahertz camera
}

By M. Bernard*, M._Romano*, A. Aouali**, A. Sommier**, J.C. Batsale** and C. Pradere**

* Epsilon company, esplanade des arts et métiers, 33405 Talence cedex, mbernard@epsilon-alcen.com, mromanoepsilon-alcen.com

** I2M Institute, UMR CNRS 5295, esplanade des arts et métiers, 33405 Talence cedex, alain.sommier@u-bordeaux.fr, abderezak.aouali@u-bordeaux.fr, jean-christophe.batsale@ubordeaux.fr and christophe.pradere@u-bordeaux.fr

\section{Abstract}

Terahertz waves have been shown to be an effective contactless, safe, and low-cost technique that allows to investigate nondestructive testing or water diffusion within porous media, such as biomaterial or insulation materials $[1,2]$. Few years ago a $\mathrm{THz}$ camera based on an infrared camera coupled with a photothermal converter was developed [3] in our group. Here we report recent advances on large image scanning and reconstruction processing. The goal is to realize A4 images from x,y scan (cf. figure 1) composed of ROI (from $0.5 \times 0.5$ to $5 \mathrm{~cm} \times 5 \mathrm{~cm}$ ). Here, the purpose of image reconstruction based on stitching algorithm is discussed associated with lock-in technique and Singular Value Decomposition for the acquisition of each single ROI.

In fact, different image processing methods were applied to improve the quality of $\mathrm{THz}$ images (cf. figure 2). First of all the 4 images method is applied. Singular Value Decomposition can be used to denoised the picture. Normalization by the beam, averaging on several periods, mean of IR image according to $\mathrm{THz}$ wavelength can also increase the image quality.

The image quality is very sensitive to the signal to noise ratio of the THz source. A simple way to increase it is to reduce the beam size to increase the power density of initial signal. If the beam is small, more scan should be done to image the same object. In this work, images were obtained with a reduced beam size, to get the best signal to noise ratio. The results obtained on the final $\mathrm{THz}$ images are super resolved compared to the ROI size, which is encouraging for further study on the system.

\section{REFERENCES}

[1] S. Zhong, Progress in terahertz nondestructive testing: A review. Sep. 2019 Frontiers of Mechanical Engineering 14(3):273-281

[2] M. Bensalem, A. Sommier, J. C. Mindeguia, J. C. Batsale and C. Pradere, Capability of THz for Thermotransmittance/water content measurements of insulating materials: heat and mass transfer. Conference QIRT 2018, Berlin, Germany, 25-29 Jun. 2018. Available on QIRT Open Archives: http://dx.doi.org/10.21611/qirt.2018.120

[3] M. Romano, A. Chulkov, A. Sommier, D. Balageas, V. Vavilov, J. C. Batsale, C. Pradere, Broadband Subterahertz Camera Based on Photothermal Conversion and IR Thermography. J Infrared Milli Terahz Waves (2016) $37: 448$ 
10.21611/qirt.2020.079

$15^{\text {th }}$ Quantitative InfraRed Thermography Conference, 6- 10 July 2020, Porto, Portugal



Fig. 1. Schema of the bench, the object is in the focal plane on X,Y stages, IR camera and TTC represent the Thz camera.

a)



b)

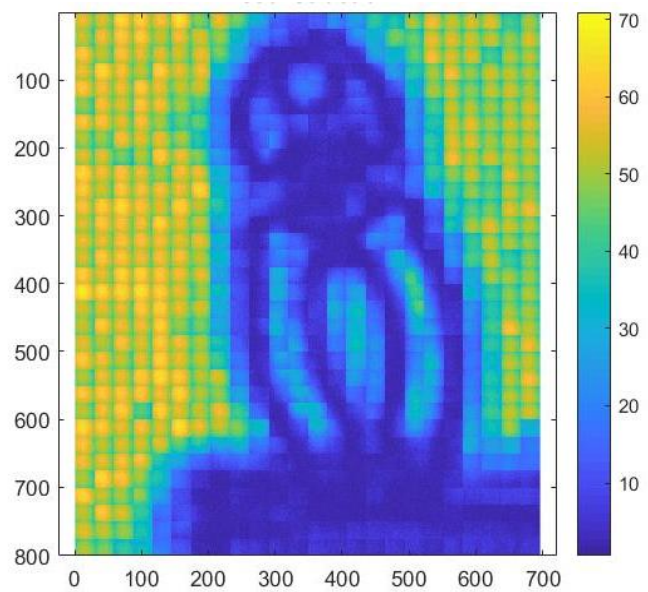

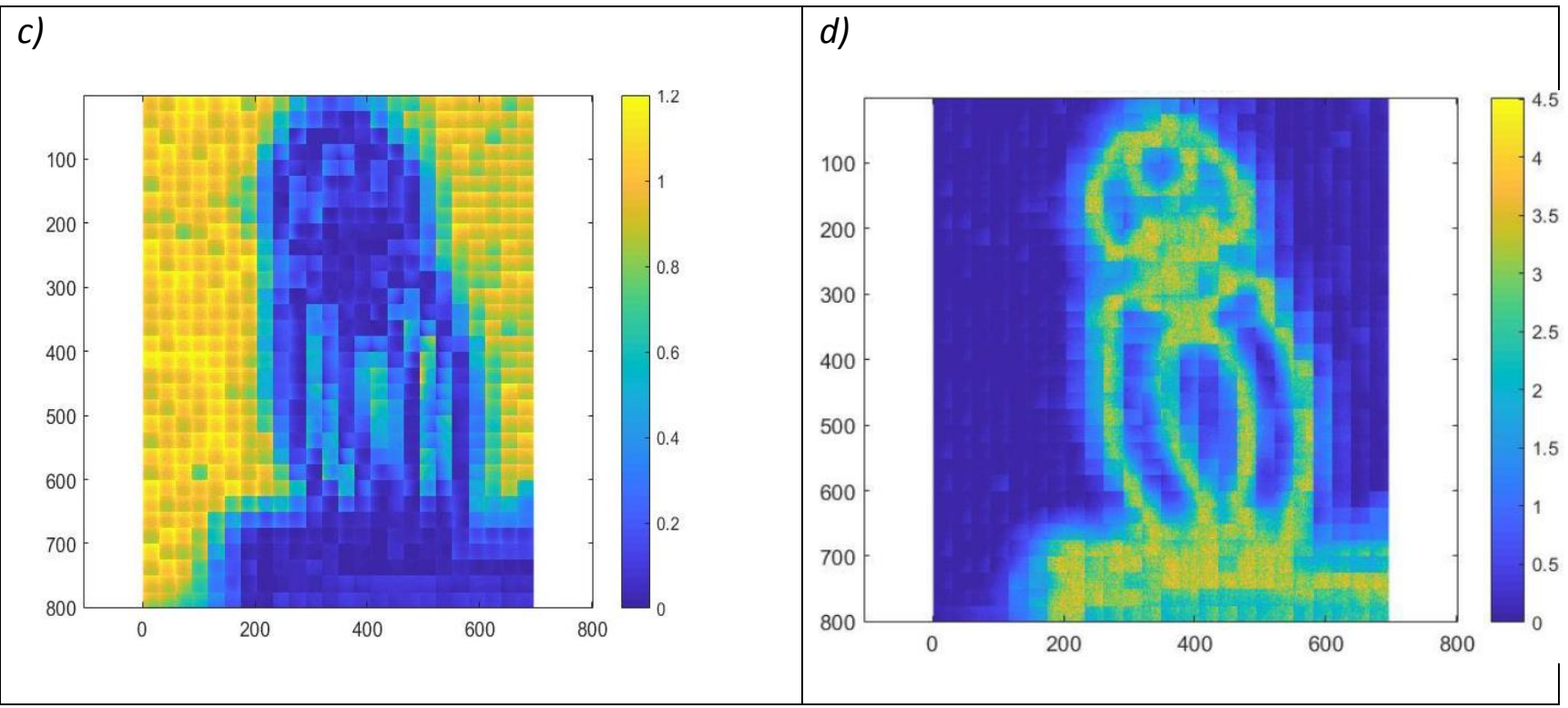

Fig. 2. Presentation of some results on a plastic tool obtained with lock-in technique based on 4 images technique: a) visible picture of the object, $b$ ) raw images, $c$ ) image of transmission, $d$ ) image of absorbance 